\title{
A mitologia do ornamento \\ e a "lição" do animal: Humboldt nas cataratas do Orenoco
}

\author{
Lúcia Ricotta Vilela Pinto ${ }^{a}$
}

\begin{abstract}
Resumo
O presente texto consiste em uma versão adaptada da apresentação que fiz durante o Seminário Monstruosas Organizações em 2017, em que retomo análises sobre o americanista Alexander von Humboldt. Existem passagens de seu Quadros da Natureza em que se constatam camadas de um discurso antropológico, quando o ornamento das urnas funerárias indígenas é visto em favor de um foco nas linhas de contato da natureza e cultura, para se transformarem na orquestração de uma mitologia interna à fantasia humana. No entanto, para além da escavação humboldtiana de um "pensamento selvagem" por meio das condições simbólicas do ornamento, há uma camada abafada em sua perspectiva antropológica que marca, no espaço colonial, uma ambivalência. Graças ao papagaio que Humboldt encontra nas cataratas do Orenoco, a língua dos extintos índios aturianos ganha contorno, constituindo os acordes do que se poderia chamar "lição" do animal, abrindo assim o começo para uma economia mitológica diversa.
\end{abstract}

Palavras-chave: Alexander von Humboldt; Colonialismo; Antropologia; Coleção; Ornamento.

Recebido em: 16/09/2018 Aceito em: 08/10/2018

aProfessora do Departamento de Letras da Universidade Federal do Estado do Rio de Janeiro (UNIRIO). E-mail: luciavilelapinto@gmail.com 


\section{Linhas de contato}

Guarnição tosca deste escolho duro

Troncos robustos são, a cuja grenha

Menos luz deve, e menos deve ar puro

A caverna profunda, do que à penha;

Caliginoso leito, é o seio obscuro

Da negra noite: a ensinar tal se empenha

Infame turba de noturnas aves,

Gemendo tristes e voando graves

(Luis de Góngora).

1 A public a ção brasileira de Quadros da Natureza, em 1953, pelos Editores W. M. Jackson Inc. é a reedição da tradução em língua portuguesa de Assis de Carvalho, de 1884, pelo Editor Eduardo Perié de Buenos Aires.

2 Alexander von Humboldt e Aimé Bonpland permanecem cinco anos viajando pela América, entre 1799 e 1804, e percorrem regiões da Venezuela, Cuba Colômbia, Equador, Peru e México. No final da viagem, têm uma breve estadia na Filadélfia nos EUA, última etapa antes do retorno à Europa. O Vues des Cordillères et Monuments des Peuples Indigènes de l'Amérique, integrando a edição monumental de trinta volumes de Voyages aux Régions Équinoxiales du Noveau Continent, fait par Alexandre de Humboldt e Aimé Bonpland entre 1799 et 1804, foi publicado entre 1810-13 na França e constitui um documento etnográfico e antropológico das culturas ameríndias. Há ilustrações de paisagens, vestuários indígenas, reproduções de monumentos astecas do México pré-colombiano, de manuscritos com escritura pictográfica, hieróglifos, ornamentos, arabescos etc.
Quando Alexander von Humboldt (1769-1859) relata no Quadros da Natureza (Ansichten der Natur) ${ }^{1}$, de 1807, seu percurso pelas cataratas de Atures e Maipures no rio Orenoco, na Amazônia colombiana, parece constituir um gabinete de curiosidades no microcosmo de algumas páginas. Matérias orgânicas, objetos inorgânicos, desenhos, vasos, técnica de mumificação e a notação do eco da palavra ameríndia num papagaio falante se avizinham nessa espécie de Wunderkammern, formando uma coleção de "documentos" americanistas do passado colonial. O acervo de objetos rituais - pedras, esqueletos, urnas mortuárias, língua morta, ornamento - próprios ao espaço de um mundo amazônico variado tem então seu valor e sentido culturalmente deslocados e reinscritos. No colecionismo humboldtiano de "monumentos dos povos indígenas da América" ${ }^{2}$, humano e não humanos, entes animados e inanimados, imagens e coisas se confundem, e modos distintos de ser encontram lugar na Amazônia. Por essa razão um mundo americanista se inscreve no extraordinário de audibilidades e visibilidades marginais, desestabilizando a ordem imperial do mundo e suas categorias culturais.

Sem enredamento narrativo unindo começo, meio e fim, curiosidades e objetos etnográficos estão dispostos de modo contingente, fora da lógica formal de representação e para além do desenlace conclusivo de um padrão historicista. Por meio de um sujeito colonialista da ciência europeia, a combinação dessas "curiosidades" e objetos etnográficos, vistos e "achados" nos caminhos amazônicos, reencena, de um lado, o trauma histórico do colonialismo e, de outro, a interrupção da linha do trajeto, 
Raúl Antelo em "A genealogia do vazio" apresenta sugestiva proposta interpretativa da passagem de $\mathrm{Humboldt}$ pelas cataratas do Orenoco, onde estabelece que a linguagem virtualmente humana do animal (do papagaio) é um arabesco opaco à razão do sujeito universal. Tal desenvolvimento conclusivo, no entanto, não é coextensivo à condição antropológica qu e $\mathrm{Hu} \mathrm{mbold}$ atribui ao ornamento como repetição das mesmas formas, a qual justamente reforça um regime moderno da universalidade ocidental. Ver 2001, p. 25-39. convocando esse mesmo sujeito civilizador à escuta de uma realidade tanto mais negligenciada quanto silenciada. Humboldt, ao lado do botanista Aimé Bonpland, de índios e outras pessoas que foram se agregando as suas muitas expedições pela Amazônia, vai decantando múltiplas sensações e calibrando os sentidos daquele mundo entre localidades, diversas regiões e os deslocamentos de um ponto a outro. No "livro segundo" de Quadros da Natureza, "Cataratas do Orenoco em Atures e Maipures", ele escreve sobre um "mundo de águas e rios" localizado entre a Colômbia, naquele ano de 1800 ainda Nova Granada, e a Venezuela. As cataratas formadas por inumeráveis quedas d'águas se sucediam e sobrepunham-se umas às outras. O ruído da queda de suas massas era terrível, conta Humboldt, e a navegação à canoa nas imediações ameaçadora pelo perigo de choque nos rochedos. Ambiente semeado de ilhas e escolhos, agitado por ondas espumantes e contracorrentes escorrendo ao sabor dos rasgos desiguais das pedras, suas concavidades e espessas covas. Na "entrada meridional do randal de Atures", havia, segundo Humboldt, uma gruta, dentro da qual se ocultava um ossário dos índios aturianos e urnas mortuárias. Flagrantes resíduos da tribo extinta. Um cemitério no buraco da pedra. Era o lugar sagrado do sacrifício.

O espaço colonial da violência aí se abre e ao mesmo tempo se fecha. Emerge como presença ambígua, dando lugar a uma opacidade ante o movimento linear, projetivo e reflexivo da razão ocidental e imperial. A "cena" da gruta aturiana, com as urnas ornamentadas, é apresentada conforme as linhas de um espaço que possibilita o encontro com uma diversidade de objetos etnográficos, sejam os desenhos à la grecque das urnas seja o papagaio falante da língua morta dos atures ${ }^{3}$. Talvez para Humboldt ali estivesse não só a "repetição rítmica das formas regulares", mas o lugar do extraordinário, do que advém e interrompe violentamente a fixidez do programa imperial, pronto a delimitar onde se é aprisionado como um exótico "Outro" e pronto a circunscrever também o sentido produzido perante o envolvimento do observador.

A presente consideração começa por estender a perspectiva da historiografia da ciência por Lorraine Daston e Katherine Park em Wonders and the Order of Nature, de modo a visibilizar, na passagem de Humboldt pelas cataratas, os afetos da curiosidade sensível, os quais se avizinham das 
convencionais operações de saber a que se submete a natureza na América. Daston e Parker apontam para a "distinta categoria ontológica" da fascinação, assombro, encantamento e espanto como o "Ur-act of cognition" (ato primevo da cognição), pois, replico suas palavras, "as therorized by medieval and early modern intellectuals, wonder was a coginitive passion, as much about knowledge as about feeling"' (DASTON; PARK, 2001, p. 14). A heartland da curiosidade de Humboldt pode ser interpretada sob a perspectiva de um contorno que atravessa muito posteriormente o sonho de uma "nova era da curiosidade," alentado por Michel Foucault, em 1980, e então repisado por Lorraine e Parker no livro mencionado. A proposta foucaultiana de um "filósofo mascarado" reabilita figuras da consciência filosófica que estariam além de sua dimensão cognitiva, que privilegia a universalidade conceitual, apontando antes para os "sinais de existência" das ideias bem como para a "fulguração das tempestades possíveis," quando se faz existir "uma obra, um livro, uma frase, uma ideia" (FOUCAULT, 2008, p. 302). Leiam-se esses desdobramentos no texto de Foucault:

Curiosidade, futilidade. A palavra, no entanto, me agrada: ela me sugere uma coisa totalmente diferente: evoca "inquietação"; evoca a responsabilidade que se assume pelo que existe e poderia existir; um sentido agudo do real, mas que jamais se imobiliza diante dele; uma prontidão para achar estranho e singular o que existe à nossa volta; uma certa obstinação em nos desfazermos de nossas familiaridades e de olhar de maneira diferente as mesmas coisas; uma paixão de apreender o que se passa e aquilo que passa; uma desenvoltura, em relação às hierarquias tradicionais, entre o importante e o essencial.

Uma virada possível do pensamento filosófico estaria na experiência do estranho e singular que rompesse com as familiaridades do sujeito e pusesse o seu pensamento na condição de objeto; nada da pura consciência e das justificativas lógicas. A curiosidade move um deslocamento crítico da racionalidade cognitiva. Tema onipresente na "evolução intelectual" de Lévi-Strauss, por exemplo, quando se autofigura

4 "como teorizado pelos intelectuais medievais e pelos primeiros intelectuais modernos, a fascinação era uma paixão cognitiva tanto do conhecimento quanto do sentimento". como etnógrafo, no modo mesmo do "desarraigamento crônico" no qual o "refúgio" da profissão o obriga a viver. A imagem do etnógrafo, observador de diferentes sociedades e culturas, baliza assim as linhas de contato, a abertura ou fechamento à dimensão ontológica de curiosidade científica a 
ser explorada no encontro com os restos materiais e simbólicos do trauma colonialista.

No capítulo "Como se faz um etnógrafo" de Tristes Trópicos, Lévi-Strauss considera a sua atração pela etnografia como a "afinidade de estrutura entre as civilizações que ela estuda e a de [seu] próprio pensamento" (LÉVI-STRAUSS, 2005, p. 51): "o etnógrafo procura conhecer e julgar o homem de um ponto de vista elevado e distante o suficiente para abstraí-lo das contingências próprias a esta sociedade ou àquela civilização" (p. 53). O problema da relação entre antropologia e colonialismo está aqui colocado ${ }^{5}$. Da tradução da diferença e das transformações entre culturas, as operações teóricas para conhecer os índios, levadas a cabo por Lévi-Strauss - seja no estudo das variáveis dinâmicas do signo seja na aplicação de seu estruturalismo -, dinamizam uma "relação do conhecimento" que começa por invalidar a antropologização do outro na mesmidade do sujeito, apontando para a "condição tradutiva intrínseca da antropologia, discurso conceitualmente codeterminado pelos discursos sobre os quais discorre" (CASTRO, 2015, p. 233). As afirmações de Lévi-Strauss de que o "conhecimento [...] consiste em uma seleção de aspectos verdadeiros [...] que coincidem com as propriedades do meu pensamento" e de que "meu pensamento é ele próprio um objeto [...] sendo 'deste mundo' participa da mesma natureza que ele" (2005, p. 53-4) sugerem já ser a experiência com o "meu pensamento" o efeito de práticas de sentido abertas por outra

5 Um rendimento amplo dos impasses do colonialismo como "a priori histórico" da antropologia o c ide ntal e stá contemporaneamente d e s d obrado e m Metafísicas Canibais: elementos para uma antropologia pósestrutural, de Eduardo Viveiros de Castro, no modo mesmo de sua proposta de “d e scolonizaçã o permanente do pensamento" que passa pela operação de incorporar a "aliança" entre "as concepções e práticas provenientes dos mundos do 'sujeito' e do 'objeto'" (Castro, 2015, p. 28). cultura. No limite extremo dessa abertura, vislumbram-se os caminhos da autoantropologia nas linhas de Patrice Maniglier e Roy Wagner, repetidas por Viveiros de Castro em Metafísicas Canibais para redefinições possíveis da antropologia perante perspectivas de mundos e ontologias plurais. De Roy Wagner a definição lapidar é "todo entendimento de uma outra cultura é um experimento com nossa própria cultura" (WAGNER, 2010, p. 41) e a de Maniglier consiste em afirmar que a antropologia "nos devolve uma imagem de nós mesmos na qual não nos reconhecemos" (CASTRO, 2015, p. 21).

\section{Mundo diverso}

Voltando a Humboldt e aos Quadros da Natureza, trata-se de acompanhar o percurso pela região de Maipures a fim de 
perceber quais seriam as dobras que propriedades comuns, "repetição rítmica das formas regulares" e ocorrência do que existe de real na Amazônia - "fato estranho"-, podem realizar em uma ciência das culturas. Leiamos a primeira parte do relato:

Na entrada sul do Raudal de Atures, na margem direita do rio, encontra-se a gruta de Ataruipa, amplamente conhecida entre os índios. A região ao redor tem um caráter de natureza grave e grandioso, o qual parece ser adequado a um funeral nacional (HUMBOLDT, 1987, p. 140).

[...]Neste lugar sombrio, abre-se a boca da gruta de Ataruipa, na verdade não é uma gruta, mas um buraco, uma pedra escarpada suspensa; uma espécie de baía quando até ali se elevavam as águas que minaram. Este lugar é o túmulo de tribos exterminadas (Völkerstammes) (HUMBOLDT, 1987, p. 141).

No buraco aberto pela forma escarpada da pedra, Humboldt descobre o túmulo dos aturianos exterminados. Cito:

Contamos aproximadamente 600 esqueletos bem conservados, em muitas cestas tecidas com as folhagens da palmeira. Essas cestas, que os índios chamam mapires, formam um tipo de sacola quadrada, que varia de acordo com a idade da pessoa falecida. Mesmo os recém-nascidos têm seu próprio mapire. Os esqueletos estão tão completos que nenhuma costela nem falange falta.

Os ossos estão de três modos preparados: parte branqueado, parte com onoto, o pigmento da Bixa Orellana, colorido de vermelho, e parte recoberto de resina aromática e envolto, como múmias, em folhas de plátano. [...] Além dos mapires ou cestas, também há urnas de argila meio cozidas, que parecem conter os ossos de famílias inteiras (HUMBOLDT, 1987, p. 141)

E agora recorto passagem em que se registram as urnas aturianas. Cito:

[...] de forma oval, esverdeada, com alças em forma de crocodilos e cobras; a borda superior está decorada com meandros e labirintos. Esses ornamentos são muito semelhantes àqueles que cobrem as paredes do palácio mexicano em Mitla. Eles são encontrados em todas as regiões, nos mais diversos estádios da cultura humana, entre os gregos e os romanos, bem como nos escudos dos taitianos e outros habitantes das ilhas do Pacífico, onde quer que a repetição rítmica das formas regulares agrade aos olhos. [...] a razão dessas semelhanças baseia-se mais em fundamentos psíquicos da natureza interior de nossa predisposição espiritual do que em igualdade de descendência e de antigos trânsitos dos povos (HUMBOLDT, 1987, p. 142) (grifo nosso). 
Humboldt, aturdido com a condição antropológica dos ornamentos indígenas na "repetição rítmica das formas regulares", pergunta aos intérpretes que o acompanham sobre a antiguidade dos vasos ${ }^{6}$. Estes respondem apoiados na tradição guarepe que:

Os valorosos aturianos, perseguidos pelos antropófagos (menschenfressenden) caribenhos, se refugiaram nos penhascos das cataratas, triste habitação, onde o desgraçado povo desapareceu com seu idioma [...], provavelmente em uma época bastante recente, pois em Maipures vi ainda, fato estranho!, um velho papagaio que os indígenas não compreendem, porque fala, segundo eles, a língua dos aturianos (HUMBOLDT, 1987, p. 142)

Definitivamente, para Humboldt, não são estas as venturosas praias da Arcádia. A utopia de um paraíso terreal na América está fora do seu horizonte. A vida tropical está atravessada pela morte, o sacrifício de povos e a violência da destruição. Humboldt diz ao final de sua passagem pelos

6 No capítulo "Ruines de la maison sépulcrale de Miguitlan ou Mitla, dans la province d'Oaxaca", de Sites de Cordillères et monuments des peuples indigènes de l'Amérique, Humboldt diz: "Les grecques du palais de Mitla présentent sans doute une analogie frappante avec celles de vases de la Grande-Grèce et avec d'autres ornements qu'on trouve répandus sur la surfasse de presque tout l'ancien continente; mais j'ai déjà fait observer, dans um autre endroit, que des analogies de ce genre prouvent trêspeu pour les anciennes communications des peuples, et que, sous toutes les zones, les hommes se sont plus à une répétition rhythmique des mêmes formes, répétition qui constitue le caractere principal de ce que nois appelons vaguement grecques, meandres et arabesques (HUMBOLDT, 1989, p. 267). cemitérios de Maipure: "[M]orrem as famílias dos homens. Desaparece o glorioso rumor dos povos". A negatividade temporal marca, portanto, a vida na América. O fim de algumas de suas histórias e o não apaziguamento do mundo natural pela razão se anunciam na dimensão espacial do território americano. Humboldt fala do "injurioso homem", uma espécie de não ser, feito animal antropológico que "há de destruir o fruto antes da sua maturidade", nas palavras dele.

Georges Baitalle em "Hegel, a morte e o sacrifício" se vale de algumas linhas do "Prefácio" à Fenomenologia do Espírito, de Hegel as quais, com efeito, ajudam a encaminhar algumas questões. As linhas são a seguintes: "A morte [...] é o que há de mais terrível e sustentar a obra da morte é o que exige a maior força [e] [o]ra, a vida do espírito não é a vida que se apavora diante da morte, e se preserva da destruição, mas a que suporta a morte e nela se conserva. [...] o Espírito só é essa potência na medida em que contempla o Negativo bem no rosto (e) se instala perto dele" (BATAILLE, 2013, p. 392). Nesse defrontar-se com a morte, afirma Bataille, o homem é lançado na negatividade, em um não é mais e não é ainda: "Ele deixa de ser como a pedra, um dado imutável", na medida em que "a força, a violência da negatividade", atuando em seu espírito, 
"o jogam no movimento incessante da história, que o muda" e que, com o poder que tem de acabar as coisas conforme a temporalização mortífera do tempo, torna tudo mortal no dissolver do tempo (BATAILLE, 2013, p. 397). "Escavando a cova sempre" (replico verso de "Nas covas de baza" de João Cabral de Melo Neto) e encontrando ossos e restos inorgânicos que, de algum modo, sustentam a morte dos aturianos, esse espaço das covas amazônicas por Humboldt se constitui num espaço de morte, do não ser ou do ser-Outro.

Humboldt inscreve a morte dos aturianos na voz do animal, a "morte que vive uma vida humana" pôde ser e se conservar no animal, incitando a produção de uma língua outra (BATAILLE, 2013, p. 395). A língua do animal, "que, não negando nada, perdido, sem oferecer oposição, em meio à animalidade global [...], não desaparece verdadeiramente..." (p. 400). É como se, na flagrante monstruosidade residual dos ossos aturianos, a espectralidade desse coletivo encarnada no "fato estranho" do "velho papagaio" que fala sua língua fizesse a linguagem se exteriorizar, cair no corpo para melhor ser ouvida, dando lugar à presença de uma língua desaparecida que, embora repetida, não atualiza as analogias que formas regulares carregam ${ }^{7}$. A língua repetida pelo papagaio amazônico não consiste na "repetição rítmica" das mesmas formas, é, antes de tudo, o "fato estranho", o túmulo que vem irradiar a aparição e a memória viva do arquivamento próprio ao humano. Gosto de pensar num reflorestamento da voz aturiana no animal, pensando que, nessa floresta amazônica, deve intervir a possibilidade de um pensamento atravessado pela escuta de outras vozes e formas e pelas ressonâncias de ontologias e mundos outros. Mas não é integralmente isso o que se passa em Humboldt, pois, com a passagem do papagaio articulada ao ornamento de "formas regulares", a torção contida na lição do animal não permite a saída de Humboldt da mitologia do ornamento. Ir mais longe na mitologia indígena não foi sua contrapartida. O movimento demonstrado no

Bataille (2013, p. 397) diz: "apenas a morte assegura a existência de um ser espiritual ou 'dialético' no sentido helegeliano". Orenoco de uma "repetição rítmica" das mesmas formas é apenas o de analogias fixamente humanas. A língua aturiana desabrigada encontrou abrigo no ornamento, dentro de uma mitologia do humano primitivo inacessível. 


\section{Ornamento, mitologia e modernidade}

Gostaria de adensar o mitológico do ornamento aturiano. O que dá a esse ornamento o seu caráter mitológico é o peso atribuído por Humboldt aos "fundamentos psíquicos da natureza interior de nossa predisposição espiritual." Justamente porque o ornamento é rigorosamente definido como repetição rítmica das mesmas formas, fonte de analogias idênticas, que ele delimita um "pensamento selvagem" sem o estruturalismo. Se a repetição simbólica ornamental fosse musical e, nesse caso, variante, o ornamento de Humboldt se desvencilharia do universal-subjetivo, o que não ocorre. É flagrante, nesse sentido, sua semelhança com o projeto moderno da globalidade humana a ser abarcada no absoluto primeiro-romântico da arte alemã. Lembra o momento de ressemantização do arabesco romântico no âmbito da "nova mitologia" ou a "mitologia indireta", por Friedrich Schlegel, que nos encaminha para Conversa sobre a poesia, em especial ao "Discurso sobre a mitologia" (1797-1803).

Friedrich Schlegel estabelece a relação entre arabesco, a humanidade do homem moderno, poesia e mitologia. A trama arabescada deve dar lugar à nova mitologia da modernidade pronta a substituir a "turba confusa dos deuses antigos", para ele, "a mais antiga e original forma da fantasia humana" (SCHLEGEL, 2016, p. 519). Seria como "suprimir o curso e as leis da razão razoavelmente pensante" para que nos puséssemos "de novo na bela confusão da fantasia", no caos originário da natureza humana, na "expressão hieroglífica da natureza circundante" (p. 518-20). A condição humana e global do ornamento está mantida. Diz Schlegel:

Creio que alguém que fosse capaz de compreender o grande processo de rejuvenescimento universal, os princípios da revolução eterna, deveria poder alcançar também os polos da humanidade, e saber reconhecer a ação dos primeiros homens, assim como o caráter da idade de ouro que ainda virá. Então cessaria o palavrório vazio, e o homem compreenderia o que ele é, e entenderia a Terra e o Sol.

É isso o que quero dizer com uma nova mitologia (SCHLEGEL, 2016, p. 522).

Infelizmente não temos acesso a nenhuma imagem das urnas funerárias que Humboldt viu, tampouco de seu ornamento. Só pela semelhança por ele notada entre o 
ornamental da urna funerária e as gregas do palácio mexicano de Mitla, do qual nos deixou uma gravura junto aos volumes de Vuès e Sites de Cordilières, podemos abarcar a modalidade de ornamento a que ele se refere. Ermano Stradelli (2009), viajante italiano que viajou pelo Orenoco, em 1887, ajunta ao relato de sua passagem por Atures e Maipures desenhos de restos de urnas funerárias ameríndias, por ele encontradas em Mairacanera, que eram parecidas, segundo afirma, com as encontradas em Atures, em caverna natural aberta na encosta do morro. Em "Urnas funerárias de povos indígenas extintos e curiosos ídolos de barro e pedra da região amazônica", Emílio Goeldi (2009) descreve escavações arqueológicas executadas na Guiana brasileira entre Oiapoque e Amazonas, em 1895: "achados de cerâmica feitos em duas cavernas funerárias artificiais construídas em forma de bota no rio Cunani". E acrescenta: "merece especial atenção a decoração exterior das urnas mortuárias - esteticamente concebida como ornamento de altíssimo valor - em meandros, espirais e desenhos de escada vermelhos e amarelos passando por dentro do traço original, que, originando-se nela, para ela retorna" (GOELDI, 2009 , p. 1). Os achados arqueológicos de Goeldi são da mesma natureza dos que permite a Humboldt ver nos meandros dos ornamentos a repetição antropológica idêntica e recursiva das "formas regulares", mas, sobretudo, o que Goeldi sublinha é o simbolismo estético na decoração exterior das urnas funerárias.

Ora, se ampliarmos mais a discussão, percebemos que a estetização simbólica do ornamento o torna contíguo à definição formalista das "belezas livres" kantianas. As matrizes de meandros e labirintos do ornamento indígena estão sendo ecoadas nos desenhos à la grecque os quais servirão a Kant para a definição filosófica da categoria transcendental de "belezas livres". A passagem do parágrafo 16, "O juízo de gosto pelo qual um objeto é declarado belo sob a condição de um conceito determinado não é puro", da Analítica do Belo é a seguinte:

os desenhos à la grecque, as folhagens para molduras ou as folhagens sobre tapeçarias de papel, e assim por diante, nada significam por si: não representam nada, nenhum objeto sob conceito determinado, e são belezas livres. Pode-se contar também aquilo que na música se denomina fantasias (sem tema), e mesmo toda a música sem texto, na mesma espécie (KANT, 1980, p. 323) (grifo nosso). 
Com base em Kant, Kerstin Behnke (1995), em Arabescos Românticos, aponta para distintas espécies de ornamento segundo sua essência não representacional e antimimética. Uma larga tradição islâmica do arabesco também pôde conservá-lo como forma pura que nada significa por si. A definição kantiana das belezas livres aparece como um princípio transcendental, pura forma moduladora de uma variação contínua, cuja lei formal é a invariância de meandros e espirais, ou, como disse Humboldt, a "repetição rítmica das formas regulares". A insistência aqui em ligar todos esses fios está relacionada à necessária redundância da linguagem ornamental. Compreende-se assim a aproximação que a definição moderna das belezas livres pode ter com a própria função distintiva a qual Lévi-Strauss, nas Mitológicas I, atribui ao mito, a saber, a função de "significar a significação" (LÉVI-STRAUSS, 2004, p. 385).

Com o ornamento humboldtiano, temos um kantismo sem a imaginação conceitual-filosófica de Kant. Afirmo isso com base no modo como Humboldt se compraz em conceber o ornamento como um movimento imanente por meio do equilíbrio da "repetição rítmica das formas regulares". O que ele fundamenta é o equilíbrio dinâmico em nossa "natureza interior" e predisposição espiritual, o centro mesmo do humano, condição para a generalidade das relações de dimensões entre as quais se ordenam a vida da natureza e a vida psíquica e espiritual. O ornamento contém uma gramática da humanidade do humano que alegoriza o sentido do que é conceitualmente inapreensível, do mesmo modo que belezas livres, a fantasia sem tema e a música sem texto "nada significam por si".

Behnke assinala igualmente a lógica de exterioridade material e ideal que incide sobre o ornamento arabescado: moldura que enquadra uma representação é, no entanto, marginal a ela. Com efeito, enquadra a representação e a toma como o seu centro significativo. Esse primeiro contexto de enquadramento da representação é, segundo Behnke, oriental, cuja concepção faz o arabesco coincidir com a "forma bela em si". O segundo contexto o entende como "arte subordinada" que tem a significação por centro. Em pesquisas etnográficas de Geoffrey Galt Halpham, citado por Behnke, o arabesco remonta "ao neolítico e constitui a mais antiga expressão artística da humanidade" (BEHNKE, 1995, p. 21). Esse apriorismo do 
ornamento é "estimulante da imaginação", pois acolhe um "fluxo hipotético", sugerido "pela forma dinâmica das linhas, continuidade do padrão como faixa contínua e ininterrupta e relação dinâmica das partes entre si" (p. 20). Tudo isso traduz o ornamento como forma pura, abstrata, dessemantizada que descentraliza e desloca o humano ao infinito e, portanto, ao sistema mítico.

Por um rendimento extemporâneo à questão aqui analisada, Costa Lima em Mimesis: desafio ao pensamento enseja sobre o arabesco uma reflexão que remonta à genealogia do sujeito na experiência kantiana da beleza. O belo, concedendo ao sujeito uma "satisfação desinteressada e livre", lança-o numa aprendizagem (um processo evolutivo de maturação) sobre como representar a "irrepresentável presença informe do real". Um tipo sui generis de evolução é preparado pela experiência estética no cerne da consciência reflexiva do sujeito. As palavras de Costa Lima, com base em argumento de Otave Chédin, sumarizam essa ideia: "A experiência da beleza, a representação que lhe seria específica, nos prepararia para o domínio do sensível. Mas apenas nos prepararia porque esse domínio só é de fato alcançado pelas leis formuláveis [do] entendimento" (LIMA, 2000, p. 182).

Dando testemunho da morte dos aturianos, desde o cemitério natural, com a presença e recuperação de ossos e esqueletos, jogos regulares de labirintos ao indizível da "perda dolorosa", Humboldt não pôde separar a morte da natureza arabescada das formas estéticas, que "nada significam por si". Assim, reservou aos "mais diversos estádios da cultura humana, entre os gregos e os romanos, bem como nos escudos dos taitianos e outros habitantes das ilhas do Pacífico [...] a repetição rítmica das formas regulares" que agrada aos olhos, "sem [a] representação de um fim". Nesse sentido, o ornamento como a mitologia moderna é expressão da fantasia artística primitiva, "uma tal obra de arte da natureza" - como denomina Friedrich Schlegel ( SCHLEGEL, 2016, p. 519) -, representando, portanto, a possibilidade de um adensamento universalista do humano desde um pensamento selvagem. Ademais, uma ética do luto está em jogo na morte aturiana, ao modo daquela desdobrada por Jean-Luc Nancy, na introdução do The birth to presence. Em face de um "ato primitivo de presença" e da "objetividade mais arcaica" do humano, ossos, esqueletos não chegam à consciência, 
escapam, portanto à representação. O luto é como "aquilo que não tem limites, nem representação. É lágrimas e cinzas. Não recupera nada, nada representa" (NANCY, 1993, p. 3). Seria como se a sobrevivência dos aturianos no eco animal, que, entretanto, se sabe incomunicável, equivalesse a manter o morto no luto (estou glosando o Nancy) ou ao nascer de sua presença, que vem ao mundo como se sempre estivesse lá. A “lição" tradutória da língua animal, que se exterioriza em sua corporeidade, implica uma inscrição na cultura apta à possibilidade de outro pensamento na voz animal-acústica do humano.

\section{REFERÊNCIAS}

ANTELO, R. Transgressão e modernidade. Ponta Grossa: Editora UEPG, 2001.

BATAILLE, G. "Hegel, a morte e o sacrifício". Tradução e apresentação de João Camillo Penna. Alea Estudos Neolatinos. Rio de Janeiro: Programa de Pós-Graduação em Letras Neolatinas, Faculdade de Letras da UFRJ, v. 15, n.2, 2013, p. 389-413.

BEHNKE, K. Arabescos românticos. Cadernos do Mestrado. Rio de Janeiro: Universidade do Estado do Rio de Janeiro, Instituto de Letras, v. 16, n. 16, 1995.

CASTRO, E. V. O nativo relativo. Mana: estudos de antropologia social. Revista de Pós-Graduação em Antropologia Social PPGAS - Museu Nacional da UFRJ, Rio de Janeiro, 8(1), 2002.

Metafísicas Canibais: elementos para uma antropologia pós-estrutural. São Paulo: Cosac Naify, 2015.

DASTON, L.;PARK, K. Wonders and the Order of Nature (11501750). New York: Zone Books, 2001.

FOUCAULT, M. “ O filósofo mascarado". Arqueologia das ciências e história dos sistemas de pensamento (Ditos e escritos II). Organização e seleção de Manoel Barros da Motta; tradução Elisa Monteiro. Rio de Janeiro: Forense Universitária, 2008.

GÓNGORA, L. de. Fábula de Polifemo e Galatéia e outro poemas. Organização e tradução de Péricles Eugênio da Silva Ramos. São Paulo: Hedra, 2008. 
GOELDI, E. Urnas funerárias de povos indígenas extintos e curiosos ídolos de barro e pedra da região amazônica. Boletim do Museu Paraense Emílio Goeldi: Ciências Humanas. Belém: Museu Paraense Emílio Goeldi, vol.4, n.1, 2009.

HUMBOLDT, A. Von. Quadros da Natureza. São Paulo, Rio de Janeiro, Porto Alegre: Editores W. M. Jackson Inc., 1953.

. Ansichten der Natur: Herausgegeben und kommentiertvon Hanno Beck. Darmstadt: Wissenschaftliche Buchgesellschaft, 1987.

Sites des Cordillères et Monuments des Peuples Indigènes de l'Amérique, integrando a edição monumental de trinta volumes de Voyages aux Régions Équinoxiales du Noveau Continent, fait par Alexandre de Humboldt e Aimé Bonpland entre 1799 et 1804. Paris: Jean-Michel Place, 1989.

KANT, I. Crítica do Juízo. Analítica do belo. Tradução de Rubens Rodrigues Torres Filho. Coleção Os Pensadores. São Paulo: Abril Cultural, 1980.

LÉVI-STRAUSS, C. O cru e o Cozido. Mitológicas I. Tradução de Beatriz Perrone-Moisés. São Paulo: Cosac Naify, 2004.

LEVI-STRAUSS, C. Tristes Trópicos. Tradução de Rosa Freire D'Aguiar. São Paulo: Cia das Letras, 6a reimpr., 2005.

LIMA, L. C. Mimesis: desafio ao pensamento. Rio de Janeiro: Civilização Brasileira, 2000.

NANCY, J-L. The birth to presence. Tradução de Brian Holmes et al. Stanford: Stanford University Press, 1993.

SCHLEGEL, F. Conversa sobre poesia. In: Fragmentos sobre poesia e literatura (1797-1803): seguido de Conversa sobre poesia. Tradução e notas Constantino Luz de Medeiros, Márcio Suzuki. São Paulo: Editora Unesp, 2016.

STRADELLI, E. Lendas e notas de viagem: a Amazônia de Ermanno Stradelli. São Paulo: Martins Fontes, 2009.

WAGNER, R. A invenção da cultura. São Paulo: Cosac Naify, 2010. 


\section{Abstract \\ A mitologia do ornamento e a "lição" do animal: Humboldt nas cataratas do Orenoco}

The present text consists of an adapted version of the presentation I made during the Seminar Monstruosas Organizações in 2017, in which I analyze again the americanist Alexander von Humboldt. There are passages from his Views of Nature in which layers of an anthropological discourse are found, when the ornament of the Indian funerary urns is seen in favor of a focus on the contact lines of nature and culture, to become the orchestration of a my thology internal to the human fantasy. However, beyond the humboldtian excavation of a "savage thought" through the symbolic conditions of ornament, there is a muffled layer in its anthropological perspective that marks the colonial space an ambivalence. Thanks to the parrot that Humboldt encounters in the Orinoco Falls, the language of the extinct Aturius Indians gains a contour, constituting the chords of what might be called the lesson of the animal, thus opening the beginning for a diverse mythological economy.

Keywords: Alexander von Humboldt; Colonialism; Anthropology; Collection; Ornament. 